\title{
O O Programa Bolsa Família e a Social-Democracia: uma análise institucional

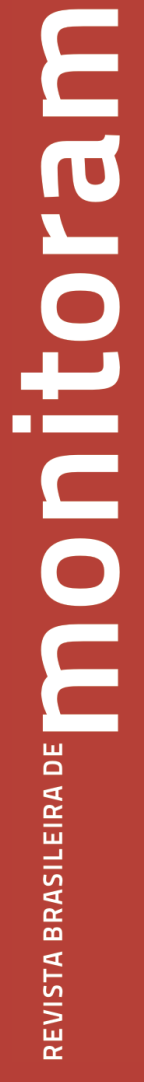




\section{Resumo}

Programas dE TRANSFERÊNCIA DE RENDA CON-

DICIONADA, COMO O BRASILEIRO BOLSA FAMÍLIA, APRESENTAM, CADA VEZ MAIS, CARACTERÍSTICAS OUUE OS APROXIMAM DE POLÍTICAS SOCIAL-DEMOCRATAS, DESENHADAS PARA UM NOVO CONTEXTO NACIONAL E MUNDiAL. Alguns trabalhos, tAIS COMO dE ESPING-ANDERSEN (2002), IDENTIFICAM DETERMINADOS PROGRAMAS DE TRANSFERÊNCIA COMO UMA ALTERNATIVA DE POLÍTICA SOCIAL PARA A PROMOÇÃO DO BEM-ESTAR. O PROGRAMA, NÃO CONTRIBUTIVO, FORTALECE O PROCESSO DE TRANSFORMAÇÃO NO PADRÃO DE PROTEÇÃO SOCIAL PREDOMINANTE NO PAÍS ATÉ OS DIAS DE HOJE. AlÉm DISSO, É UM DOS PRINCIPAIS RESPONSÁVEIS PELA OQUEDA DA DESIGUALDADE E AUMENTO DA RENDA. ESSES FATORES, BEM COMO A SUA SUSTENTAÇÃO POLÍTICA NA ESFERA ELEITORAL, EVIDENCIAM A EXISTÊNCIA DE UMA AGENDA DE POLÍTICA SOCIAL PRÓPRIA DA CENTRO-ESOUERDA.

\begin{abstract}
CONDITIONAL CASH TRANSFERS PROGRAMS, SUCH AS the Brazilian Bolsa família, nOW SHOW CHARACTERISTICS THAT MAKE THEM CLOSER TO A PATTERN OF SOCIAL-DEMOCRATIC POLICIES FROM A NEW CONTEXT. SOME AUTHORS, SUCH AS ESPING-ANDERSEN (2002), CLASSIFY SOME CASH TRANSFER PROGRAMS AS AN ALTERNATIVE POLICY TO PROMOTE SOCIAL WELFARE. THE POLICY IS NON-CONTRIBUTORY, CHANGING THE MODEL OF THE SOCIAL PROTECTION WHICH HAS PREVAILED IN THE COUNTRY UNTIL THOSE DAYS. MOREOVER, BOLSA FAMILIA IS ONE OF THE MAIN REASONS FOR DECREASE IN INEQUALITY AND INCOME INCREASE. THESE FACTORS, AS WELL AS ASPECTS THAT RELATE THIS SOCIAL POLICY TO THE POLITICS, CONFIRM THE EXISTENCE OF A CENTER-LEFT SOCIAL POLICY AGENDA.
\end{abstract}

\section{PALAVRAS-CHAVE:}

Estado de Bem-Estar; Social-Democracia; política social; transferência de renda; Bolsa-Família; pobreza; desigualdade. 


\section{O contexto}

A partir dos anos 80, uma série de países latino-americanos passou por importantes processos de democratização e redemocratização, entre eles Brasil, Argentina, Uruguai, México, Peru e Chile. Também nesse novo contexto mundial, vivendo uma nova ordem econômica, tais países não só tiveram que reordenar seu posicionamento internacional, como se viram diante do aumento acentuado da pobreza e indigência em seus territórios. Na América Latina, nos anos 1990, $48,4 \%$ de seus habitantes estavam abaixo da linha de pobreza; $22,6 \%$ viviam na extrema pobreza.

Neste momento, ficou claro que as velhas políticas sociais aplicadas na região, algumas até de qualidade relativa, mas a maioria delas elitizada, concentrada em grupos reduzidos e de caráter primordialmente regressivo, não eram capazes de atender às demandas de estratos sociais historicamente alijados dos serviços e benefícios providos pelo Estado. Era indispensável ampliar a participação pública nesta esfera. No entanto, os governos encontravam-se com recursos reduzidos e limitados não apenas por suas próprias restrições orçamentárias, mas também devido a cobranças por parte de organismos internacionais, tais como o Fundo Monetário Internacional (FMI).
Assim, havia um conjunto de fatores que conduziam a uma mudança na estrutura das políticas sociais. O primeiro deles advinha da própria necessidade dos cidadãos de verem atendidos os seus direitos de uma vida digna mínima. O processo de redemocratização, com ampliação do direito de escolha dos representantes, bem como contando com avanços tecnológicos e logísticos, que permitiam uma eleição mais fidedigna às vontades do eleitorado, fazia com que esses grupos fossem capazes de ampliar a sua influência política, mesmo que de maneira descoordenada. A política social deveria ser revista.

"A democratização trouxe à esfera política novas estratégias de ação. A política social é um dos planos onde isso pode ser observado, na medida em que decisões políticas sobre o setor têm profundo impacto sobre ganhos eleitorais", afirmam Coutinho e Santanna (2008) sobre os novos programas de proteção social na região.

Outro aspecto fundamental no contexto dos anos 1980 foi a crise financeira e econômica por que passavam os países desenvolvidos e também os periféricos. Esse processo fazia com que houvesse uma série de restrições orçamentárias para a aplicação de programas 
universalizados, os quais pudessem atender a milhões de cidadãos desassistidos em um momento de desemprego - e informalidade laboral - em níveis bastante acentuados, como era o caso latino-americano.

A partir dos anos 1990, na região, partidos de esquerda e centro-esquerda - alguns associados a sindicatos, estruturados, contando com apoio de grupos tradicionalmente mal representados e sem ligações estreitas com os velhos ranços clientelistas - começaram a ampliar sua presença no Legislativo e, em muitos casos, alcançar mesmo a presidência de diferentes países.

A despeito de algumas acusações pontuais de populismo, partidos com um viés mais à esquerda lograram ocupar a presidência em alguns países e, com isso, passaram a ter que promover políticas as quais, em alguma medida, atendessem às necessidades primeiras destes cidadãos, seus eleitores.

Como se trata de uma região que, mais que pela pobreza, é conhecida por sua enorme desigualdade, era necessário desenvolver uma agenda de políticas de caráter combativo à pobreza e também à desigualdade. Com essa plataforma política, para que cumpris- sem tais propósitos, os partidos de esquerda e centro-esquerda foram eleitos.

Nesse contexto, no início dos anos 1990 surgiu uma nova geração de políticas sociais na América Latina: os Programas de Transferência Condicionada (PTC), os quais tinham por característica fundamental serem uma política não apenas condicionada, mas também focalizada, não universal. Os PTC buscam atender famílias com crianças, abaixo de uma determinada linha de pobreza e exigindo contrapartidas tais como presença na escola e vacinação (como o exemplo brasileiro). Na região, a exigência de presença mínima na escola é recorrente, variando entre $80 \%$ e 90\%, e há também cobranças quanto ao atendimento de saúde².

Com essas características, tais programas foram amplamente apoiados pelos organismos e bancos de fomento internacionais, tais como o Banco Mundial e instituições ligadas à Organização das Nações Unidas (ONU). Viraram uma política social constante nas agendas dos mais variados países, inclusive sendo um modelo exportado para outras regiões.

Em boa parte, segundo apontam alguns estudos, especificamente no caso brasileiro Soa- 
res e Sátyro (2009) e Barros et al (2006), eles são responsáveis pela queda da desigualdade e aumento da renda. Em alguns casos, colaboraram com aumento da escolaridade, segundo avaliações feitas. No caso do Brasil, tal impacto não foi considerado tão relevante.

Ainda que ocorram amplas discussões sobre a natureza e o impacto dos PTC, bem como sobre a atual política social implementada por governos de centro-esquerda na América Latina, algumas linhas de estudo consideram que este cenário vem significando um novo paradigma nos modelos de Estado de Bem-Estar. Uma gama de autores trabalha com pesquisas sobre o nascimento (ou fortalecimento) de uma linha social-democrata na América Latina ${ }^{3}$. Segundo tais autores, entre outros aspectos, governos eleitos nos últimos anos, de centro-esquerda e de origem trabalhista, acabam por implementar, adaptar ou reforçar políticas tradicionalmente aplicadas e desenvolvidas por partidos da social-democracia europeia.

Esping-Andersen (2001; 2002), estudando os rumos da social-democracia e aceitando a necessidade de novos modelos de políticas de proteção social, identifica a possibilidade de que os PTC possam integrar a agenda de políticas dos Estados de Bem-Estar. Entre as opções que garantiriam melhor destino aos recursos mais escassos estão os programas de transferência, os quais representariam uma alternativa de instrumento para a promoção do bem-estar, principalmente no que diz respeito às futuras gerações.
Fatores como atenção à criança e à educação são listados como características importantes neste tipo de iniciativa. $\mathrm{O}$ autor cita nominalmente o caso do Programa Bolsa Família (PBF).

Não obstante avaliações positivas do modelo, grande abrangência, boa aprovação do eleitorado e bons resultados, os PTC, mais visível inovação da política social na região, têm sofrido duras críticas ${ }^{4}$. Elas vêm principalmente de setores mais à direita, que enxergam resquícios de velhas propostas clientelistas e acusam-nos de induzir ao "efeito preguiça"; mas também por parte da esquerda, que condena políticas não universais que ampliem o papel do Estado como provedor de bens, em vez de fortalecer sua atuação na provisão de serviços, tais como saúde e educação.

Apesar disso, a proposta deste artigo é de que o PBF, no seu formato de PTC pode, sim, integrar um quadro de políticas social-democratas aplicadas na América Latina. Isso porque diante das transformações nas políticas da social-democracia, decorrentes da globalização e de um momento de maior escassez de recursos, mudaram não apenas as alianças dos partidos social-democratas mas também a natureza das suas políticas de promoção do bem-estar. Manteve-se a preocupação com a igualdade e com um Estado responsável por interceder na melhoria da provisão de bens e serviços para estratos sociais que se encontram mais vulneráveis às intempéries do mercado. 


\section{NASCIMENTO DA SOCIAL- DEMOCRACIA E OS ESTADOS DE BEM- ESTAR EUROPEUS}

Governos social-democratas foram eleitos na Europa na primeira metade do século $X X$, muitos no pós-guerra. Os primeiros ideários da social-democracia, porém, remontam ao fim do século XIX. Tais premissas - ainda que sem tal denominação - surgem como uma flexibilização proposta por Eduardo Bernstein de algumas das teorias do socialismo. 0 "Socialismo Evolucionário" de Bernstein tinha um propósito inicial: refutar o que considerava utopia na teoria marxista, concentrando esforços nos elementos "realistas e idealistas" do movimento socialista. Para ele, era necessário ampliar os direitos sociais, políticos e econômicos dos trabalhadores alemães. Aí residiam a verdadeira transformação e o real caminho para a conquista do poder.

As ideias defendidas por Bernstein, a gênese da social-democracia, compreendiam políticas que tinham relação direta com a melhoria do bem-estar do trabalhador, entendido naquele momento como o homem provedor. Nesse sentido, já em sua origem, a social-de- mocracia contempla dois aspectos fundamentais na sua definição: trata-se de um modelo de governar que une a transformação pelo sistema, bem como visa a reduzir as desigualdades que emergem da própria lógica do sistema capitalista. O Estado Social-Democrata desenha-se como aquele que existe dentro do capitalismo, porém intervém tentando reduzir os efeitos de mercado. A melhoria no bem-estar do indivíduo acaba traduzindo-se em melhoria para a sociedade como um todo.

A social-democracia encontrou seu grande espaço na Europa do pós-guerra. Com os países arrasados diante da catástrofe, viu-se a necessidade de um Estado que fosse capaz de reduzir os riscos para seus cidadãos. Entre seus objetivos estavam não apenas as políticas de proteção social mas também políticas macroeconômicas de controle monetário, de pleno emprego e de coordenação de salários.

Em "Three Words of Welfare Capitalism" (1990), Esping-Andersen, concentrado nos estudos de países europeus, apresenta sua consagrada classificação de três modelos ideais para o Estado de Bem-Estar ${ }^{5}$.

\section{3 (Huber, 1996; Lanzaro, 2009.)}

4 Os partidos, mais recentemente, deixaram de se posicionar contra o programa em si, ainda que questionem, em alguma medida, aspectos de sua aplicação relacionados com as condicionalidades e com as chamadas "portas de saída".

5 Em linhas gerais, no Liberal o mercado é o maior provedor, são poucas transferências universais e aposentadorias para poucos beneficiados. O Continental/Corporativista é contributivo e também seletivo. O Social-Democrata, por sua vez, garante direitos sociais universais; o Estado é o grande responsável pelo bem-estar dos seus cidadãos. A ideia é de que todos pagam, todos se beneficiam.

Revista Brasileira de Monitoramento e Avaliação | Número 4 | Julho-Dezembro de 2012 
Ainda que alguns autores tenham baseado-se nessa tipologia para avaliar os casos de países latino-americanos, incluindo o exemplo brasileiro, trata-se de realidades econômicas, sociais e partidárias bastante distintas. $\mathrm{O}$ que se assemelha, sim, atualmente, com relação a esse cenário, é a amplitude da democracia e seus impactos na demanda de políticas sociais. A própria idéia do Welfare na Europa surgiu em um contexto de demanda por ampliação dos direitos sociais ${ }^{6}$. Não se constitui mais em uma questão de alívio da pobreza via caridade, mas, sim, em um sistema que garanta direitos sociais àqueles que adquiriram direitos políticos com a democracia.

Castles e Pierson (2007) afirmam que boa parte dos Estados modernos pode ser considerada hoje um Estado de Bem-Estar, ainda que não na mesma medida dos países europeus. Cabe, portanto, avaliar de forma não preconceituosa, sem estabelecer um modelo como o ponto ótimo ou único referencial. No caso latino-americano, inovações de política social estão sendo buscadas e difundidas, de tal forma a ampliar a gama de instrumentos aplicados.

\section{SOCIAL-DEMOCRACIA E POLÍTICAS DE BEM-ESTAR NA AMÉRICA LATINA E NO BRASIL}

Na América Latina, tradicionalmente, as políticas sociais foram mais desenvolvidas nos países com mais tradição democrática, como Chile, Uruguai e Costa Rica? ${ }^{7}$ Contudo, houve outro padrão que acabou determinando po- líticas de proteção social com características bem mais aproximadas de um perfil contributivo/bismarkiano. Esses foram os casos do Brasil e da Argentina, que começaram a desenhar políticas de proteção durante os anos dos governos de Getúlio Vargas e Juan Perón na primeira metade do século passado. O legado institucional garantia direitos relativamente ampliados, porém restritos a grupos específicos de trabalhadores formais.

Os propósitos dessas políticas foram, em larga medida, utilizá-las como vias para o controle das classes trabalhadoras pelo Estado. Para funcionar de maneira eficaz e minimamente justa, esse modelo contributivo tem a prerrogativa de altas taxas de emprego e de formalidade. Mesmo com essas dificuldades, o modelo, que privilegiava grupos específicos e restritos, desamparando completamente milhões de cidadãos, manteve-se e foi fortalecido por décadas.

Os anos 1980 e 1990 foram cruciais no que diz respeito às políticas de bem-estar no mundo, sejam elas relativas às provisões de bens (pensões, seguro-desemprego) ou de serviços (cobertura de saúde, de educação). Na América Latina, vindos de períodos de governos autoritários, os anos foram de democratização, redemocratização e de necessidade de políticas sociais urgentes para, ao menos, tentar cobrir um enorme déficit existente no que diz respeito à mínima proteção dos cidadãos. Por outro lado, o neoliberalismo também se apresentou com todo seu vigor no campo da economia. 
O Brasil, após o fim da ditadura militar e da fracassada ideia de fazer o bolo crescer para depois repartir, começou a enfrentar, de um lado, uma forte demanda da população por proteção social; e, de outro, sucessivos problemas financeiros, incluindo a moratória da dívida externa. Diante desse quadro, o país precisou expandir suas políticas sociais, mesmo com pouca disponibilidade de recursos.

No campo das disputas políticas, após o impeachment de Fernando Collor, em setembro de 1992, o Brasil passou a viver dias de maior estabilidade democrática com a eleição de Fernando Henrique Cardoso, do Partido da Social Democracia Brasileira (PSDB)8, que assume o poder em 1995, ficando por dois mandatos, até a eleição de Luiz Inácio Lula da Silva, do Partido dos Trabalhadores (PT), em 2003, e finalmente a atual presidenta, Dilma Rousseff, em 2010.

O movimento em direção à esquerda não foi exclusivo do Brasil. Lanzaro (2009) chama a atenção para a chegada de partidos de esquerda e centro-esquerda no poder na Amé- rica Latina, no que classifica como a "social-democracia criolla". Ele define tais governos como "compostos por partidos de esquerda - de filiação socialista, reformista ou revolucionária - (...) que assumiram as regras da democracia representativa de tradição liberal e se encaixam nos parâmetros da economia capitalista". E, dada essa restrição, "esses governos tratam de promover políticas públicas estratégicas". Seriam elas que compensariam as restrições econômicas do sistema vigente.

Devido às restrições nas opções de política econômica, que estavam então bastante condicionadas a uma agenda ortodoxa de austeridade fiscal e controle da inflação, tais partidos de esquerda ou centro-esquerda viram-se tolhidos na aplicação de parte dos seus programas tradicionais de governo. No que tange à proteção social, por sua vez, tais políticas são de mais fácil execução, sem sofrer grandes limitações. Foi justamente na proteção social que esses partidos conseguiram atuar de maneira mais intensa no que diz respeito ao seu objetivo maior de promover a igualdade e a inclusão.

\section{6 (Marshall, 1963.)}

7 (Huber, 1996.)

8 Ainda que o partido seja denominado Partido da Social Democracia Brasileira, uma série de autores reconhece seu governo com características que mais o aproximam do centro no espectro político que propriamente de uma social-democracia, de centro-esquerda.

Revista Brasileira de Monitoramento e Avaliação | Número 4 | Julho-Dezembro de 2012 


\section{GÊNESE E DESENVOLVIMENTO DO BOLSA FAMÍLIA}

A Constituição de 88, a Carta Magna da redemocratização, é de fundamental importância para entender o processo de transformação por que vem passando a proteção social no Brasil. Nela, foram inseridos e ampliados diversos direitos dos cidadãos brasileiros. A Carta, segundo Huber (1996), criou "fundações para um Estado de Bem-Estar universalista". Antes disso, em 1971, o Brasil já havia sido o primeiro a criar uma aposentadoria não contributiva para o setor rural, mas não tinha avançado muito além. "Na medida em que a Constituição reconheceu o direito à aposentadoria não integralmente contributiva dos trabalhadores rurais em regime de economia familiar - garantindo transferência de solidariedade -, ela também, por definição, começou a criar um sistema de políticas sociais redistributivas, ainda que pleno de lacunas." $\mathrm{A}$ Constituição instituiu também o direito a uma renda para idosos e portadores de deficiência em extrema pobreza: o Benefício de Prestação Continuada (BPC).

Se os primeiros sinais do que viria a ser o PBF surgiram em 1995 em experiências locais, na esfera federal o primeiro programa de transferência foi o que tinha como objetivo combater o trabalho infantil, o Programa de Erradicação do Trabalho Infantil (Peti), focalizado em crianças expostas às ameaças do trabalho de risco. Ele foi instituído em 1996, portan- to ainda no governo de Fernando Henrique. Foi o governo do PSDB também que criou, em 2001, o Bolsa Escola, inspirado no programa de Brasília. Depois dele, veio o Bolsa Alimentação e, por fim, o Cartão Alimentação, esse já no governo Lula.

Com tamanha profusão de programas de transferência, havia problemas de coordenação, cadastro e, por conseguinte, de focalização. Diante disso, já no primeiro ano do PT no poder, o governo federal decidiu unificar os programas criando o PBF. Além desses quatro programas de assistência social, foi incluído também o Vale Gás, programa de subsídio ao gás de cozinha. O modelo permaneceu não contributivo (financiado através de impostos), focalizado e condicionado.

A partir de então, o PBF passou a ser de responsabilidade do Ministério do Desenvolvimento Social e Combate à Fome (MDS). Hoje o PBF atende mais de 13 milhões de famílias, ou seja, em torno de um quarto da população.

Formalmente, os objetivos do PBF são: alívio da pobreza e desigualdade por meio de transferências monetárias para famílias pobres; quebra da transmissão intergeracional de pobreza mediante incentivos em capital humano; ajuda no empoderamento dos beneficiários ao aproximá-los dos serviços complementares de saúde e educação. 
Segundo Draibe (2009), o PBF encaixa-se no que é chamado PTC por apresentar as seguintes características: trata-se de um programa do tipo auxílio monetário não contributivo; a transferência é utilizada com vistas a modificar comportamentos individuais; o benefício é entregue preferencialmente às mulheres, mas destina-se a toda a família; os beneficiados são famílias muito pobres, muitas delas com filhos em idade escolar; exige contrapartidas por parte dos beneficiários (a maioria delas relativa à educação e saúde).

No tocante à focalização, ainda que ela continue existindo, há muito já pode ser considerada, no Brasil, uma espécie de "universalização inteligente", porque a abrangência e o modelo ultrapassaram números que os pudessem classificar dentro de um contexto de restrições. Ele atende a mais de $50 \%$ da população de Maranhão, Piauí, Ceará, Alagoas, Paraíba e Pernambuco e 40\% dos habitantes de Bahia, Roraima, Acre, Tocantins, Rio Grande do Norte e Sergipe ${ }^{10}$.

A intersetorialidade é apontada como um dos fatores fundamentais para o bom desenvolvimento dos PTC, porque se entende que uma das principais características desejadas destas políticas é a capacidade de integrar o cidadão ao sistema de proteção de cunho universalista. O PBF, então, torna-se importante aliado na ligação entre o Estado e o cidadão, por meio de programas de saúde, educação e nutrição, entre tantos outros, podendo estar até mesmo incluídos programas de inserção laboral. Espera-se que haja uma sinergia, facilitando assim a saída dos círculos viciosos de pobreza ${ }^{11}$.

Um documento preparado para o Banco Mundial ${ }^{12}$ ressalta o caráter unificador não apenas vertical (ou seja, unindo programas antes dispersos), mas também horizontal, na sua capacidade de levar aos beneficiários os demais serviços oferecidos pelo Estado. As condicionalidades acabam sendo vistas como instrumentos capazes de fazer com que os cidadãos de mais baixa renda busquem seus direitos. Isso porque, historicamente, o acesso universal à educação e à saúde jamais significou o real acesso universal a esses serviços prestados pelo Estado.

Ainda que tenha largo alcance, o programa tem um orçamento baixo. Segundo calculam Soares e Sátyro (2009), cerca de R\$ 10,6 biIhões ou $0,37 \%$ do $\mathrm{PIB}^{13}$. Isso acaba por faci-

9 (Soares e Sátyro, 2009.)

10 Dados extraídos de Amorim Neto e Santos (2012).

11 (Draibe, 2009.)

12 (Lindert et al., 2007.)

13 Para 2012, Frischtak calculava 0,41\% do PIB. Em 2013, segundo o MDS, a previsão de gasto era de R\$ 24,9 bilhões.

Revista Brasileira de Monitoramento e Avaliação | Número 4 | Julho-Dezembro de 2012 
litar a sua implementação não apenas no que tange às restrições fiscais, mas também na relativa aceitação por parte dos contribuintes que garantem, por meio do pagamento de impostos, o financiamento de um benefício do qual não necessariamente desfrutam.

\section{BOLSA FAMÍLIA: UM PROGRAMA DA SOCIAL-DEMOCRACIA}

Originalmente, a maioria das abordagens que diziam respeito às políticas de bem-estar afirmava que só poderiam ser assim classificadas aquelas com atendimento universal, não estigmatizante. A leitura era de que o gasto excessivo de um Estado com a focalização, pelo perfil da política, mantinha o caráter estratificado da sociedade, em pouco ou nada contribuindo para a desmercantilização do trabalho ${ }^{14}$.

No entanto, alguns modelos diferentes passam a ser considerados passíveis de tal classificação. Segundo relata Jonas Pontusson (2005), a focalização vem se tornando política mais constante mesmo em países não liberais, com a menor disponibilidade de recursos para promover políticas sociais. Opta-se por canalizar os esforços para os efetivamente mais necessitados.

Uma diferença básica das propostas liberais para as social-democratas, considerando um espectro direita $x$ esquerda ${ }^{15}$, é de que seu objetivo inicial não passa pela prerrogativa da igualdade, pois é da natureza liberal entender a desigualdade como parte do processo capitalista.
Os efeitos de tal intenção ficam claros na resposta da queda do índice de Gini atribuída ao benefício. De acordo com Soares e Sátyro (2009), entre 1995 e 2004, o PBF foi responsável por $19 \%$ da queda de três pontos do índice de Gini, apesar de equivaler a meros $0,5 \%$ da renda das famílias. Entre 2004 e 2006, a participação do PBF na redução da desigualdade manteve-se tão relevante quanto no período anterior. Quanto à redução da pobreza, ele, porém, não tem surtido grande efeito. Mas é de fundamental importância quando se trata de diminuição das faixas de extrema pobreza.

\begin{tabular}{|lcc|}
\hline DECOMPOSIÇÃO DA QUEDA DO COEFICIENTE DE GINI \\
\hline \multicolumn{1}{|c|}{$\begin{array}{c}\text { TI- } \\
\text { TIPO DE RENDA }\end{array}$} & $\begin{array}{c}2004^{-} \\
2004\end{array}$ & 2006 \\
\hline Renda domiciliar per capita & $100 \%$ & $100 \%$ \\
\hline Renda do trabalho & $73 \%$ & $32 \%$ \\
\hline Aposentadorias e pensões públicas & $10 \%$ & $37 \%$ \\
\hline Outros rendimentos (capital) & $11 \%$ & $-4 \%$ \\
\hline BPC-LOAS & $7 \%$ & $14 \%$ \\
\hline Bolsa Família & $19 \%$ & $21 \%$ \\
\hline
\end{tabular}

Fonte: Soares e Sátyro (2009).

Ainda que o PTC brasileiro não tenha na sua lógica a ideia de um benefício em que todos pagam e todos são beneficiados, exibindo a marca de consenso da sociedade comum ao modelo social-democrata, ele tem por característica romper com uma tradição de benefícios contributivos no País, apresentando um caráter de transferência progressivo. Pela existência de altos índices de informalidade, acaba se diferenciando também com essa 
proposta de que não será um benefício que requererá a participação por meio de contribuições por parte do trabalhador ${ }^{16}$.

Outro aspecto deve ser levado em conta: o direcionamento da política no sentido do combate à pobreza infantil. Essa preocupação no seu desenho evidencia importante avanço no que tange às melhorias das condições para gerações futuras, diminuindo a exposição aos riscos herdados. O fato de o benefício ser dado preferencialmente à mulher também representa uma inovação que moderniza a política, pois colabora, ainda que de forma tímida e gerando alguma controvérsia, com a emancipação feminina ${ }^{17}$.

Amélia Cohn e Ana Fonseca, ambas diretamente ligadas à execução do programa $\mathrm{PBF}^{18}$, em artigo de 2004 publicado pela Fundação Perseu Abramo (do próprio PT), destacam pontos que diferenciam o PBF de outros programas de alívio de pobreza que foram aplicados ao longo da história brasileira. Esses aspectos por elas ressaltados aproximam-no de um modelo social-democrata de política social: integrado e com vistas à emancipação no longo prazo.

Entre as características relevantes são destacadas: a integração das políticas setoriais, também tratando os estados e municípios como "efetivos parceiros" na tarefa. Pelo formato do programa, a pobreza perde seu caráter pontual e, ainda que não conduza a um aspecto de emancipação imediato, ele acaba gerando riqueza local e consequente desenvolvimento descentralizado. A questão da intersetorialidade é vista como de suma importância, reconhecendo-se, outrossim, que ainda ocorrem muitos problemas na oferta de serviços.

14 (Esping-Andersen, 1990.)

15 (Bobbio, 1995.)

16 Isso vai ocorrer apenas indiretamente, com o pagamento pelos beneficiários, por exemplo, de impostos sobre produtos e serviços, os quais acabam revertendo para o financiamento do PBF.

17 Alguns autores argumentam que, ao conceder o benefício à mulher e dela cobrar o cumprimento das condicionalidades, 0 programa a estaria sobrecarregando de responsabilidades.

18 Amélia Cohn era, então, diretora de Monitoramento e Avaliação da Secretaria-Executiva do PBF e Ana Fonseca, secretária-executiva do programa.

Revista Brasileira de Monitoramento e Avaliação | Número 4 | Julho-Dezembro de 2012 
De acordo com as autoras, os avanços foram a intervenção não individual, mas familiar; o entendimento de que os programas de transferência de renda não são suficientes por si só, necessitando da presença do Estado em outras esferas, com a oferta de serviços universais; a busca pela parceria com estados e municípios; e, o mais relevante na percepção de Cohn e Fonseca, "ter como eixo a preocupação com a dimensão republicana - a criação de critérios públicos e universais de inclusão e exclusão no programa, orientados por uma concepção não punitiva, mas contratual quanto às condicionalidades". O Estado não abre mão de seu papel, ao contrário, reconhece a necessidade da sua presença.

Do lado da constituição política, estudos tais como Zucco (2008) apontam que o programa acabou por modificar a base eleitoral do partido no governo, ampliando a presença desses beneficiados na esfera política.

Assim sendo, a nova realidade política no País apresenta sintomas de novos tempos da relação sociedade-Estado, abrindo espaço para um modelo político social-democrata, com a chegada ao governo (em várias de suas instâncias) de um partido e de grupos ligados aos trabalhadores ${ }^{19}$. Nesse mesmo caminho, que conduz a um cenário de social-democracia, está a criação de fóruns nacionais, que trazem a sociedade civil à participação. A cidadania amplia-se.
Todos esses elementos reunidos, o PBF apresenta características em sua concepção - e prática - que o aproximam das novas políticas definidas como social-democratas ou de centro-esquerda. São elas: a redução da desigualdade como um propósito, o aspecto não contributivo, a atenção à criança, a concentração do benefício em um arranjo nacional, não local e, acima de tudo, por sua dimensão, uma "universalização inteligente", tendo em vista que cerca de $25 \%$ da população é beneficiada. Se não ocorre ainda o tão esperado consenso interclasses, a desmercantilização do trabalho, mesmo que só verificada de forma precária, já dá seus primeiros sinais.

\section{POR FIM}

Não é de agora que o Brasil vem desenvolvendo políticas de proteção social. Ao contrário, o processo vem de longe. No entanto, duas grandes mudanças ocorrem no contexto atual. A primeira: a participação no poder de grupos articulados no desenvolvimento da política, não mais obedecendo necessariamente a um padrão de cima para baixo. Também se deve incluir a chegada à presidência de um partido ligado à classe de trabalhadores, o qual traz consigo uma agenda política de centro-esquerda distinta e própria.

Os exemplos na história demonstram que uma política de Welfare não necessita da presença de partidos social-democratas. No entanto, 
estes partidos podem priorizar modelos que apresentem um caráter mais acentuado de busca pela igualdade. Assim, é preciso reforçar a percepção de que o espaço da disputa partidária continua sendo de fundamental importância na decisão e aplicação das políticas típicas da social-democracia ${ }^{20}$ não apenas na Europa mas também na América Latina e no Brasil, significando diferentes padrões de distribuição de preferências e alocação de recursos. Consensos políticos e instituições fortes são fundamentais como forma de levar adiante políticas bem sucedidas de bem-estar, as quais consigam atingir objetivos de igualdade sem condenar a eficiência. A política importa e faz diferença, pois ainda é nesta arena que ocorrem o debate, a resolução de conflitos e o estabelecimento de agendas em busca do desenvolvimento.
A capacidade progressiva do programa na redistribuição dos recursos, revertendo um quadro que vínhamos pintando há décadas, traz consigo algo de transformador em um sistema com um caráter notadamente conhecido por sua regressividade. Os números evidenciam que a política teve forte impacto na redução da desigualdade recente.

O PBF, dadas suas características e amplitude, pode ser considerado uma política inovadora e bem-sucedida. Não que seja suficiente ou que não mereça correções. Mas, certamente, apresenta avanços no que diz respeito às políticas de redução de risco. Mais progressiva, mais moderna, menos clientelista: uma política social-democrata de novos tempos. 
AMORIM NETO, Octavio; SANTOS, Fabiano. Brazil's social-democratic experience (19852010). In: CONGRESSO DE CIÊNCIA POLÍTICA DA IPSA, XXII, Madri, 2012. Mimeografado.

BARROS, R. P.; CARVALHO, M.; FRANCO, S.; MENDONÇA, R. A queda recente da desigualdade de renda no Brasil. Ipea, 2007.(Texto para Discussão n. 1258).

BARROS, Ricardo Paes; CARVALHO, Mirela; FRANCO, Samuel e MENDONÇA, Rosane. Sobre a queda recente na desigualdade de renda no Brasil. Documento apresentado em seminário em Brasília em 2006.

BERNSTEIN, Eduard. Socialismo Evolucionário. Rio de Janeiro: Jorge Zahar, 1997.

BOBBIO, Norberto. Direita e Esquerda - razões e significados para uma distinção política. São Paulo: Ed.Unesp, 1995.

BOSCHI, Renato. Corporativismo societal - a democratização do Estado e as bases social-democratas do capitalismo brasileiro, Revista Insight, n. 48, Págs.84-103, 2010.

BOIX, Charles. Political Parties, Growth and Equality: Conservative and Social Democratic Economic Strategies in the World Economy. Cambridge: Cambridge University Press, 1998.

BRASIL. Ministério do Desenvolvimento Social e Combate à Fome (MDS). Bolsa Família. Disponível em: < http://www.mds.gov.br/bolsafamilia/> Acesso em: 25 de jul. 2013.
COUTINHO, Marcelo; SANTANNA, Julia. Estados de Reacomodação Social: Política e Políticas de Combate à Pobreza na América do Sul. Estudos e cenários OPSA. Rio de Janeiro, 2008.

DRAIBE, Sonia. Programas de transferência condicionada de renda. In: CARDOSO, Fernando Henrique; FOXLEY, Alejandro (Coord.). América Latina: desafios da democracia e do desenvolvimento - políticas sociais para além da crise. Rio de Janeiro: Elsevier; São Paulo: iFHC, 2009.

ESPING-ANDERSEN, Gosta et al. Why We Need a New Welfare State. Oxford: Oxford University Press, 2002.

ESPING-ANDERSEN, Gosta. A Welfare State for the Twenty-First Century (2001). The Welfare State Reader. Cambridge: Polity Press, 2007.

ESPING-ANDERSEN, Gosta (Ed.). Welfare States in Transition. UNRISD, 1996.

ESPING-ANDERSEN, Gosta. Three Worlds of Welfare Capitalism. Princeton: Princeton University Press, 1990.

FRISCHTAK, Claudio. A Social-democracia brasileira: seu momento de definição. In: FÓRUM NACIONAL, XXIV - RUMO AO BRASIL DESENVOLVIDO, Rio de Janeiro, 2012. Mimeografado.

GARRETT, Geoffrey. Partisan Politics in the Global Economy. Cambridge: Cambridge University Press, 1998. 
HAGGARD, Stephan; KAUFMAN, Robert R. Development, democracy, and welfare states - Latin America, East Asia and Eastern Europe. Princeton: Princeton University Press, 2008.

HUBER, Evelyne. Options for Social Policy in Latin America: Neoliberal versus Social Democratic Models. Welfare States in Transition. UNRISD, 1996.

KITSCHELT, Herbert. The Transformation of European Social Democracy. New York, Cambridge University Press. 1994.

LANZARO, Jorge. La social democracia criolla. Análise de Conjuntura OPSA, Rio de Janeiro, $n$. 03, 2009.

LINDERT, Kathy et al.. The nuts and bolts of Brazil's Bolsa Família Program: implementing conditional cash transfers in a decentralized context. Washington: Banco Mundial, 2007. (Discusion Paper 709).

MACHINEA, José Luis; TITELMAN, Daniel e UTHOFF, Andras (Orgs). La protección social de cara al futuro: acceso, financiamiento y solidaridad. Documento apresentado no 31 período de sessões da CEPAL. Montevidéu, 2006.
MARSHALL, TH. Citizenship and Social Class (1963). The Welfare State Reader. Cambridge: Polity Press, 2007.

SADER, Emir; GARCIA, Marco Aurélio (Orgs). Brasil, entre o passado e o futuro. São Paulo: Editora Fundação Perseu Abramo: Boitempo, 2010. SOARES, Sergei; SÁTYRO, Natália. O Programa Bolsa Família: desenho institucional, impactos e possibilidades futuras. Ipea , 2009. (Texto para Discussão n.1424)

PIERSON, Christopher; CASTLES, Francis. Introdução. The Welfare State Reader. Cambridge, Polity Press, 2007.

PONTUSSON, Jonas. Inequality and Prosperity. Cornell University Press, 2005.

SACHS, Jeffrey. Los populistas también pueden tener razón. Nueva Mayoria, 2006.

TAVARES, J. A. Giusti (Org). 0 que esperar da social democracia no Brasil?. Instituto Teotônio Vilela, 2003.

ZUCCO, Cesar. The President's 'New' Constituency : Lula and the Pragmatic Vote in Brazil's 2006 Presidential Elections. Journal of Latin American Studies, 40, págs. 29-49, 2008. 